\title{
Fusarium graminearum Isolates from Wheat and Maize in New York Show Similar Range of Aggressiveness and Toxigenicity in Cross-Species Pathogenicity Tests
}

\author{
Paulo R. Kuhnem, Emerson M. Del Ponte, Yanhong Dong, and Gary C. Bergstrom
}

\begin{abstract}
First and fourth authors: Plant Pathology and Plant-Microbe Biology Section, School of Integrative Plant Science, Cornell University, Ithaca, NY 14853-5904; first and second authors: Departamento de Fitossanidade, Universidade Federal do Rio Grande do Sul, Porto Alegre, RS 91540000; and third author: Department of Plant Pathology, University of Minnesota, St. Paul 55108.
\end{abstract}

Current address of E. M. Del Ponte: Departamento de Fitopatologia, Universidade Federal de Viçosa, Viçosa, MG, Brazil $36570-900$.

Accepted for publication 10 October 2014.

\begin{abstract}
Kuhnem, P. R., Del Ponte, E. M., Dong, Y., and Bergstrom, G. C. 2015. Fusarium graminearum isolates from wheat and maize in New York show similar range of aggressiveness and toxigenicity in cross-species pathogenicity tests. Phytopathology 105:441-448.

This study aimed to assess whether pathogenic Fusarium graminearum isolates from wheat and maize were more aggressive on their host of origin and whether aggressiveness was influenced further by Btrichothecene chemotype. Fifteen isolates were selected from a contemporary collection of isolates surveyed in New York in 2011 to 2012 to represent diversity of host of origin and chemotype. Three pathogenicity assays were used to evaluate and compare these isolates. Fusarium head blight (FHB) severity and trichothecene production in wheat, and maize seedling blight were evaluated in greenhouse inoculation experiments, and Gibberella ear rot (GER) severity and trichothecene production were evaluated in maize ears inoculated in the field. Our results showed

among $F$. graminearum isolates a wide variation in aggressiveness and mycotoxin production toward wheat and maize and these isolates could not be structured by their host of origin or by chemotype. Moreover, aggressiveness rank order changed according to the host/organ evaluated. This indicates that relative susceptibility at the seedling stage may not predict susceptibility of ears. Significant correlations were observed of total trichothecenes (deoxynivalenol [DON] and its acetylated derivatives) produced with FHB and GER severity on wheat and maize, respectively. One isolate did not produce DON or ADON in wheat or maize kernels, yet was aggressive on both hosts. Nine of the fifteen isolates produced small amounts of zearalenone (ZON) in maize kernels, but not in wheat kernels, and ZON level was not correlated with GER severity. F. graminearum isolates from New York showed wide variation in aggressiveness and mycotoxin production toward susceptible wheat and maize. Neither host of origin nor trichothecene chemotype appeared to structure the populations we sampled.
\end{abstract}

Fusarium graminearum, the most important member of the $F$. graminearum species complex, is the main pathogen causing Fusarium head blight (FHB) in wheat and Gibberella ear rot (GER) and Gibberella stalk rot (GSR) in maize in North America $(35,42)$. Species of this complex are also the cause of seedling blight and root and crown rots in both crops $(41,43)$. When infecting the kernels of these crops, mycotoxins produced by the fungus may accumulate to levels that make grain and byproducts unacceptable for animal and human consumption $(35,47)$. The B-trichothecene mycotoxins deoxynivalenol (DON) and nivalenol (NIV) and the estrogenic mycotoxin zearalenone ( $\mathrm{ZON}$ ) are of greatest concern to human and animal health (14).

In contrast to North America where $F$. graminearum is the predominant species associated with FHB, GER, and GSR, pathogenic populations in other regions are composed of different or multiple species in the $F$. graminearum species complex, including F. meridionale, F. asiaticum, F. boothi, and $F$. cortaderiae $(7,21,31,54)$. The reasons for such differences among production regions worldwide are not entirely clear, but it has been suggested that migration, host preference, and/or ecological adaptation and climate may be key factors $(4,7,31)$. In addition, the toxigenic potential of isolates has been considered to influence the dynamics and spread of more fit populations into certain geographic regions

Corresponding author: G. C. Bergstrom; E-mail address: gcb3@cornell.edu

http://dx.doi.org/10.1094/PHYTO-07-14-0208-R

(c) 2015 The American Phytopathological Society
(63). Three strain-specific profiles of trichothecene production (chemotypes) have been identified within the $F$. graminearum species complex: (i) NIV and its acetyl-derivatives, (ii) DON and primarily 3-acetyl-deoxynivalenol (3-ADON), and (iii) DON and primarily $15-\mathrm{ADON}$ (40). Recent studies on wheat suggested that $F$. graminearum of the 3-ADON chemotype represented a more competitive population based on documented chemotype shifts from 15-ADON to 3-ADON in the United States and Canada, together with fitness-related factors, including aggressiveness and toxigenic potential. The handful of studies on the topic $(25,50,57)$ provided inconsistent results likely influenced by the number of individuals examined, host of origin, and the phenotypic traits assessed, including measures of pathogenic or saprophytic fitness and toxigenicity.

Aggressiveness, a measure of the level of disease caused by a pathogen, is an important trait to assess pathogenic fitness. It is determined based on pathogenicity assays conducted in controlled or field environments on one or more host species/ organs, thus resulting in different measures of aggressiveness $(27,38,48,49,57,65)$. In wheat, aggressiveness of isolates is more commonly evaluated under greenhouse conditions with inoculation of the central spikelet $(16,57)$. In maize, GER is evaluated through silk channel and kernel puncture inoculations $(28,38)$. Seeds of these two crops can be inoculated and isolate aggressiveness determined based on measures of reduced germination and emergence, seedling death, and seed-to-seedling transmission $(2,43,65)$. Whether $F$. graminearum isolates from regions where both corn and wheat are grown behave similarly or lack specialization when causing different diseases (seedling, stalk or 
spike/ear) in these hosts is not clear since most studies focus on single measures of aggressiveness in a specific host $(49,65)$.

In North America, conservation tillage has increased in recent decades, and maintenance of crop residues may affect the dynamics and structure of F. graminearum populations (22). Overwintered crop debris such as maize stalks and wheat straw are the main reservoir for $F$. graminearum and primary inoculum for FHB and GER epidemics $(22,45,46)$. Population structure studies suggested that local $F$. graminearum populations represent subsets of a metapopulation in North America (68), but some genetic isolation may occur on a regional scale (55). Whether pathogenic $F$. graminearum isolates from wheat and maize are more aggressive on their host of origin and whether an isolate's aggressiveness is influenced further by its B-trichothecene chemotype is not well understood (34). The 3-ADON and 15-ADON chemotypes of $F$. graminearum are found in both crops in the wheat- and maizeproducing areas of western New York (G. C. Bergstrom, unpublished data).

Utilizing an arbitrary selection of fungal isolates from this region, we sought to gain insights on whether $F$. graminearum populations are differentiated by their host of origin in terms of pathogenicity and toxigenic potential in these crops. The objectives of our work were (i) to assess whether the isolates are more fit pathogenically or produce higher amounts of mycotoxins when causing the disease in their host of origin and (ii) to compare the aggressiveness and trichothecene production of 3-ADON and 15-ADON chemotypes of $F$. graminearum isolated from symptomatic wheat heads and maize ears.

\section{MATERIALS AND METHODS}

Collection of isolates and pathogenicity tests. Fifteen F. graminearum isolates, seven from symptomatic wheat spikes and eight from maize ears, were used in the study (Table 1). These isolates were selected arbitrarily from a larger collection of isolates surveyed in New York in 2011-12 growing seasons (G. C. Bergstrom, unpublished data), and had their B-trichothecene chemotype predicted by polymerase chain reaction (PCR) assays targeting portions of Tri3 and Tri12 genes (62). Among the isolates from maize, four isolates were of the $15-\mathrm{ADON}$ and the others were of the 3-ADON genotype. Among the isolates from wheat, four isolates were of the 15-ADON and three isolates were of the 3-ADON genotype. An additional 15-ADON isolate from wheat (Gz014NY98), highly aggressive and a potent DON/15-ADON producer, and utilized for several years as inoculum for fungicide and cultivar evaluations in New York, was included as a reference

TABLE 1. Information for 16 Fusarium graminearum isolates evaluated for aggressiveness in field (maize ears) and greenhouse (maize seedling and wheat heads) experiments in Ithaca, 2013

\begin{tabular}{lcccr}
\hline Number & Isolate ID & Year & Host of origin & Genotype $^{\mathrm{a}}$ \\
\hline Gz830NY & 830 & 2011 & Maize & 3-ADON \\
Gz955NY & 955 & 2012 & Maize & 3-ADON \\
Gz970NY & 970 & 2012 & Maize & $3-A D O N$ \\
Gz982NY & 982 & 2012 & Maize & $3-A D O N$ \\
Gz829NY & 829 & 2011 & Maize & $15-A D O N$ \\
Gz835NY & 835 & 2011 & Maize & $15-A D O N$ \\
Gz941NY & 941 & 2012 & Maize & $15-A D O N$ \\
Gz978NY & 978 & 2012 & Maize & $15-A D O N$ \\
Gz014NY & 014 & 1998 & Wheat & $15-A D O N$ \\
Gz438NY & 438 & 2011 & Wheat & $3-A D O N$ \\
Gz479NY & 479 & 2011 & Wheat & $3-A D O N$ \\
Gz603NY & 603 & 2011 & Wheat & $3-A D O N$ \\
Gz443NY & 443 & 2011 & Wheat & $15-A D O N$ \\
Gz446NY & 446 & 2011 & Wheat & $15-A D O N$ \\
Gz478NY & 478 & 2011 & Wheat & $15-A D O N$ \\
Gz859NY & 859 & 2011 & Wheat & $15-A D O N$ \\
\hline
\end{tabular}

a Trichothecene genotyping by Tri3 and Tri12 primers. isolate. All isolates were derived from single conidia and cultures were stored in glycerol at $-80^{\circ} \mathrm{C}$.

Three pathogenicity assays were used to evaluate and compare the isolates. FHB severity and trichothecene production in wheat and maize seedling blight (MSB) were evaluated in greenhouse inoculation experiments. GER severity and trichothecene production were evaluated in maize ears inoculated in the field.

FHB and mycotoxin production in wheat. Seeds of 'Norm', a spring wheat variety highly susceptible to FHB, were sown in 6-inch diameter clay pots (7 seeds/pot) filled with soilless Cornell Mix (3.4 $\mathrm{ft}^{3}$ of compressed peat moss, $4 \mathrm{ft}^{3}$ of vermiculite, 20 lbs. of dolomitic limestone, $6 \mathrm{lbs}$. of 11-5-11 fertilizer). Plants were grown for 2 months in the greenhouse, at 20 to $25^{\circ} \mathrm{C}$ air temperature and a $14 \mathrm{~h}$ photoperiod of supplemental florescent light, and were trimmed to keep five main tillers in each pot. Potted plants were maintained in the greenhouse from planting to inoculation. Wheat heads were inoculated at early milk stage (Zadoks 73), previously determined as the most susceptible stage in 'Norm' (18). A spore suspension of each isolate was prepared by growing isolates on potato dextrose agar (PDA) for 10 days with a 12-h dark/light cycle. The macroconidia were filtered with layers of cheesecloth to reduce the amount of mycelial fragments present in the inoculum. The macroconidial suspension was then quantified using a hemacytometer. Sterile water was added to the inoculum to achieve the desired macroconidia concentrations $\left(5 \times 10^{4}\right.$ macroconidia/ml). The central spikelet of each spike was marked and a $20-\mu \mathrm{l}$ drop of the spore suspension $\left(5 \times 10^{4}\right.$ macroconidia $\left./ \mathrm{ml}\right)$ was placed inside the spikelet (23). Pots were individually covered with a plastic bag and kept for $48 \mathrm{~h}$ in a growth chamber set at $24^{\circ} \mathrm{C}$ and $14 \mathrm{~h}$ of light. The bags were then removed and the plants returned to the greenhouse until maturity. Aggressiveness of the isolates was determined based on FHB severity, or the percentage of diseased spikelets per inoculated spike, at 10 days after inoculation. Four replicates (potted plant) were used per isolate.

The amounts of DON, 15-ADON, 3-ADON, and ZON by each of the 16 isolates were assessed from a pooled sample of kernels from all four replicates and were quantified using a gas chromatographymass spectrometry (GC-MS) based methodology as described by Jin et al. (29). In brief, each pooled sample of kernels was ground using a coffee grinder and then homogenized. A 4-g subsample of kernels was extracted with $16 \mathrm{ml}$ of acetonitrile/water (84/16, vol/ vol). The sample was placed on a shaker for $1 \mathrm{~h}$, and then $4 \mathrm{ml}$ of extract was passed through a column packed with $\mathrm{C} 18$ and aluminum oxide $(1 / 3, \mathrm{wt} / \mathrm{wt})$. One milliliter of the filtrate was evaporated to dryness under nitrogen at room temperature and derivatized by silylating reagent (TMSI/TMCS, 100/1) for GC-MS analyses (Shimadzu GCMS-QP2010, Shimadzu Corporation, Kyoto, Japan). A J\&W DB-5MS capillary column $(30 \mathrm{~m} \times$ $0.25 \mathrm{~mm} \times 0.25 \mu \mathrm{m}$ ) was used in the GC system. A splitless injection mode was used with injection volume of $1 \mu \mathrm{l}$. The pressure flow control mode was used with the following oven temperature program for DON, 3-ADON, 15-ADON, and NIV analyses: $150^{\circ} \mathrm{C}$ for $1 \mathrm{~min}$ and $30^{\circ} \mathrm{C} / \mathrm{min}$ to $280^{\circ} \mathrm{C}$ holding $4 \mathrm{~min}$. Injection, ion source, and interface temperatures were kept at 260, 250, and $280^{\circ} \mathrm{C}$, respectively. The following fragment ions $(\mathrm{m} / \mathrm{z})$ were used for their quantitation: 235, 259, and 422 for DON; 377 and 392 for 3-ADON; 193 and 392 for $15-A D O N$; and 289 and 379 for NIV. For $\mathrm{ZON}$, the linear velocity flow control mode was used with the following oven temperature program: $80^{\circ} \mathrm{C}$ for $1 \mathrm{~min}$ and $50^{\circ} \mathrm{C} / \mathrm{min}$ to $300^{\circ} \mathrm{C}$ holding $5 \mathrm{~min}$. Injection, ion source and interface temperatures were kept at 290,220 , and $300^{\circ} \mathrm{C}$, respectively. The fragment ions $(\mathrm{m} / \mathrm{z})$ of 333 and 462 were used for the quantitation of ZON.

GER and mycotoxin production in maize grain. During the 2013 growing season, seeds of Monsanto hybrid DKC45-51, a GER-susceptible maize hybrid, were planted in a field at the Cornell University Musgrave Research Farm in Aurora, New York. The experiment was repeated, with each of two planting dates (20day difference) considered an independent experiment. 
The experimental design was a randomized complete block with four replicates per isolate. Each plot consisted of a 4-m long row ( $75 \mathrm{~cm}$ between rows) with 12 plants. The central eight plants of each row were inoculated. All plots were bordered by rows of the same maize hybrid. Fertilization and weed control were made according to local recommendations.

A spore suspension of each isolate was prepared as described above and elsewhere (51). At 4 days after silk emergence (52), plants were individually inoculated by injecting the suspensions $\left(2 \mathrm{ml}\right.$ of a $5 \times 10^{5}$ macroconidia/ml) or sterile distilled water (control) into the silk channel of the primary ear (51) using a syringe with an obtuse needle. The days the inoculations were performed were followed by three consecutive rainy days.

The plots were harvested 9 weeks after inoculation. The ears were handpicked and husked, and the severity score on each ear was rated as a percentage area of the ear symptomatic (52). The ears were dried at $65^{\circ} \mathrm{C}$ until $13 \%$ humidity and weighed. Maize kernels from all experiments and replicates performed with an individual isolate were combined for mycotoxin analysis ( $25 \mathrm{~g}$ of sample) following the same procedures described above.

MSB. Nontreated seeds of Monsanto hybrid DKC59-90, a maize genotype known as susceptible to GER, were inoculated with each isolate following a seed immersion-based protocol (64). The inoculum consisted of spore suspension $\left(1 \times 10^{6}\right.$ macroconidia $\left./ \mathrm{ml}\right)$ obtained from 10-day-old cultures of individual $F$. graminearum isolates grown on PDA+A (antibiotic) at $23^{\circ} \mathrm{C}$ under bright fluorescent lights. Seeds were surface-disinfested $(2 \mathrm{~min}$ in $0.5 \%$ $\mathrm{NaOCl}$ and rinsed twice for $1 \mathrm{~min}$ in sterile distilled water), placed on sterile paper towels and allowed to dry in a laminar flow hood. After drying, seeds were placed in 250-ml Erlenmeyer flasks (100 seeds/flask) containing $100 \mathrm{ml}$ of spore suspension or sterile distilled water (check treatment). The flasks were shaken at $125 \mathrm{rpm}$ for $12 \mathrm{~h}$. Then, both inoculated and noninoculated seeds were removed and dried on sterile paper towels in a laminar flow hood.

Twenty inoculated seeds were placed directly on PDA+A to determine infestation rate. Forty seeds were surface-disinfested ( $5 \mathrm{~min}$ in $70 \%$ ethanol, $5 \mathrm{~min}$ in $0.5 \% \mathrm{NaOCl}$, and rinsed twice for $2 \mathrm{~min}$ in sterile distilled water), dried, and placed on the same media to determine infection rate. These seed were incubated at $23^{\circ} \mathrm{C}$ under darkness for 6 days. The rates were determined based on the proportion of colonized seeds. In order to assess whether the inoculation method affected germination, seed germination on PDA $+\mathrm{A}$ was assessed in 20 inoculated seeds from each treatment (isolate); seeds were considered germinated if the radicle was $>5 \mathrm{~mm}$ long (43).

Seeds were sown in 6-inch diameter clay pots ( 10 seeds/pot $)$ filled with soilless Cornell Mix ( $3.4 \mathrm{ft}^{3}$ of compressed peat moss, $4 \mathrm{ft}^{3}$ of vermiculite, $20 \mathrm{lbs}$. of dolomitic limestone, $6 \mathrm{lbs}$. of 11-5-11 fertilizer). Four pots were used as replicates for each isolate. Potted plants were grown for 14 days in the greenhouse at 20 to $25^{\circ} \mathrm{C}$ air temperature and under 14-h light period. During this period plants were watered daily with tap water.

Fourteen days after sowing, four variables were evaluated: seedling emergence rate (seedling with $>2 \mathrm{~mm}$ shoot size above the ground), seedling blight incidence (shoot or the radicle visibly rotted), length of shoot and radicle $(\mathrm{cm})$, and dry weight of shoot and radicle $(\mathrm{g})$.

Data analysis. All experiments were conducted in a randomized complete block design and were repeated in independent tests. The reference isolate (Gz014NY98) was not included in the analysis since it has been previously characterized as highly aggressive and toxigenic. Because normality (Shapiro-Wilks) and homogeneity of variance (Levene's) could be assumed, analysis of variance was used and experiment included as a fixed factor showed no statistical difference $(P>0.05)$ and hence data from both experiments were combined. Two orthogonal contrasts were used to compare isolates from maize versus those from wheat and isolates of the 3-ADON versus $15-A D O N$ chemotypes. Significance of the contrasts was evaluated via a randomization test (10,000 permutations) (59).

\section{RESULTS}

FHB and mycotoxin production in wheat. Mean FHB severity differed among isolates $(P<0.001)$, ranging from 26.6 to $62.9 \%$ (Fig. 1A). When groups of isolates were contrasted, no difference in mean FHB severity was found between isolates originating from wheat and those originating from maize $(P=$ 0.140 ) and also between isolates of the 3-ADON and those of the 5-ADON isolates $(P=0.132)$ (Fig. 1A). All but one isolate $(\mathrm{Gz} 830)$ produced mainly DON at levels ranging from 10.65 to $97.05 \mu \mathrm{g} / \mathrm{g}$ (Fig. 2A) and smaller amounts of the DON acetylated derivatives form predicted by PCR assay, i.e., 15-ADON and 3-ADON genotypes produced mainly DON/15-ADON and DON/3-ADON, respectively. Some $15-\mathrm{ADON}$ isolates also produced trace levels of 3-ADON (Fig. 2A). Means of total trichothecenes (DON +
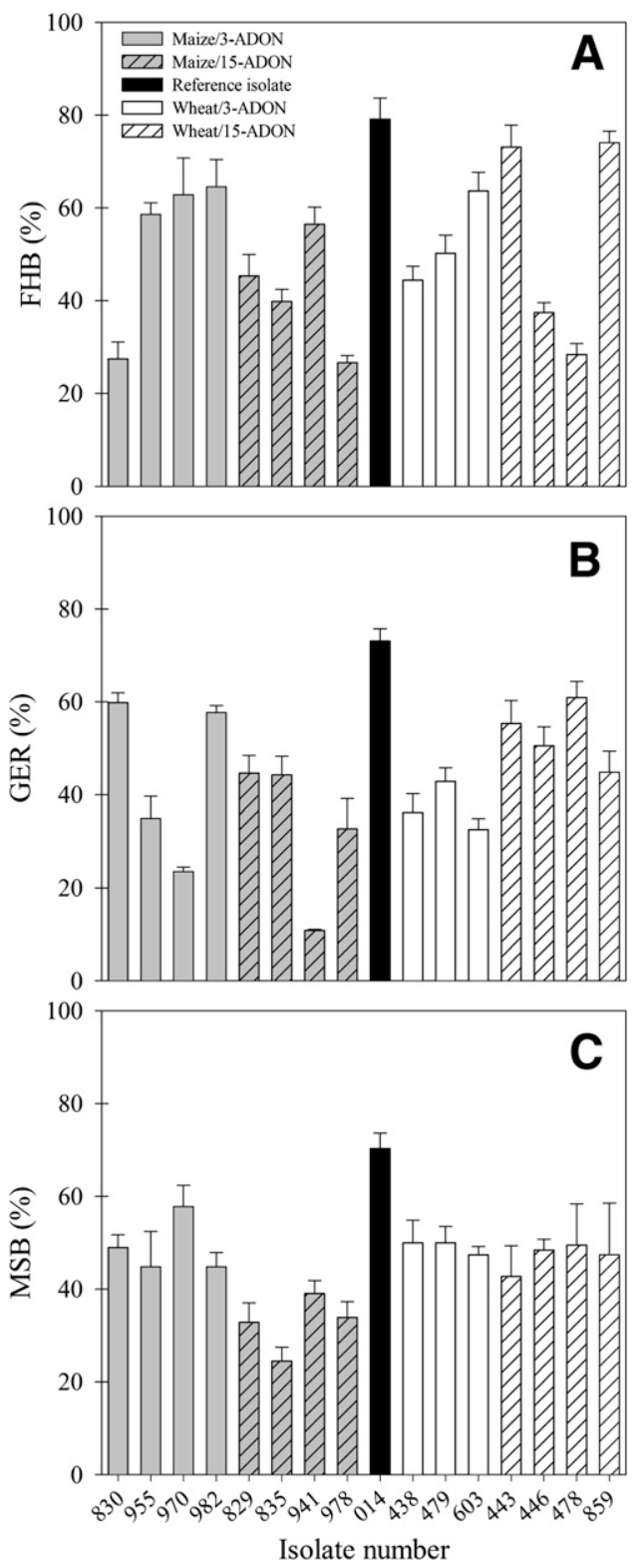

Fig. 1. Severity of A, Fusarium head blight on wheat, B, Gibberella ear rot on maize, and $\mathbf{C}$, incidence of maize seedling blight caused by Fusarium graminearum isolates from wheat spikes and maize ears and of the 3-acetyldeoxivalenol (3-ADON) and 15-ADON trichothecene chemotypes. 
acetylated derivatives $)$ did not differ $(P=0.678)$ between isolates from wheat $(60.1 \mu \mathrm{g} / \mathrm{g})$ and maize $(39.2 \mu \mathrm{g} / \mathrm{g})$ and between 3-ADON $(53.1 \mu \mathrm{g} / \mathrm{g})$ and 15-ADON (47.6 $\mu \mathrm{g} / \mathrm{g})$ isolates (Fig. 2A). The isolates did not produce any detectable level of ZON (Fig. 2A).

GER and mycotoxin production in maize. In the maize field trial, all isolates produced the typical GER symptoms with severity varying significantly among the isolates $(P<0.001)$, and with the highest mean severity $(73 \%)$ for the reference isolate (Gz014) (Fig. 1B). Mean GER severity did not differ between isolates grouped by host origin $(P=0.081)$ and by trichothecene genotype $(P=0.644)$ (Fig. 1B). Mean relative reduction in grain weight differed slightly among isolates from wheat (35\% reduction) and maize (29\% reduction), but did not differ between 3-ADON and 15 -ADON isolates $(P=0.153)$ (data not shown).

Because of the large variance in DON levels for isolates of the same group by host of origin, no difference was found $(P=0.054)$ for the mean of DON between these two host groups. Although only marginally not significant at $P=0.050$, isolates from wheat (73.96 $\mu \mathrm{g} / \mathrm{g}$ ) produced on average $30 \mu \mathrm{g} / \mathrm{g}$ of DON more than maize isolates (44.57 $\mu \mathrm{g} / \mathrm{g}$ ) (Fig. 2B). All but one isolate (Gz830) produced $\mathrm{DON}$ in mature kernels at levels ranging from 5.9 to $132.2 \mu \mathrm{g} / \mathrm{g}$ and also $3-\mathrm{ADON}$ or $15-\mathrm{ADON}$ at lower amounts, depending on the trichothecene genotype (Fig. 2B). A few 3-ADON isolates produced higher amounts of the respective acetylated derivatives than 15-ADON isolates did (Fig. 2B), but no difference was found between these two chemotype groups $(P=0.431)$. Four 3-ADON, five 15-ADON isolates, and the reference isolate (Gz014) produced detectable and similar levels $(P=0.561)$ of $\mathrm{ZON}$, ranging from 0.08 to $1.0 \mu \mathrm{g} / \mathrm{g}$ (Fig. 2B). No difference was found $(P>0.05)$ in the amount of $\mathrm{ZON}$ between these two groups.

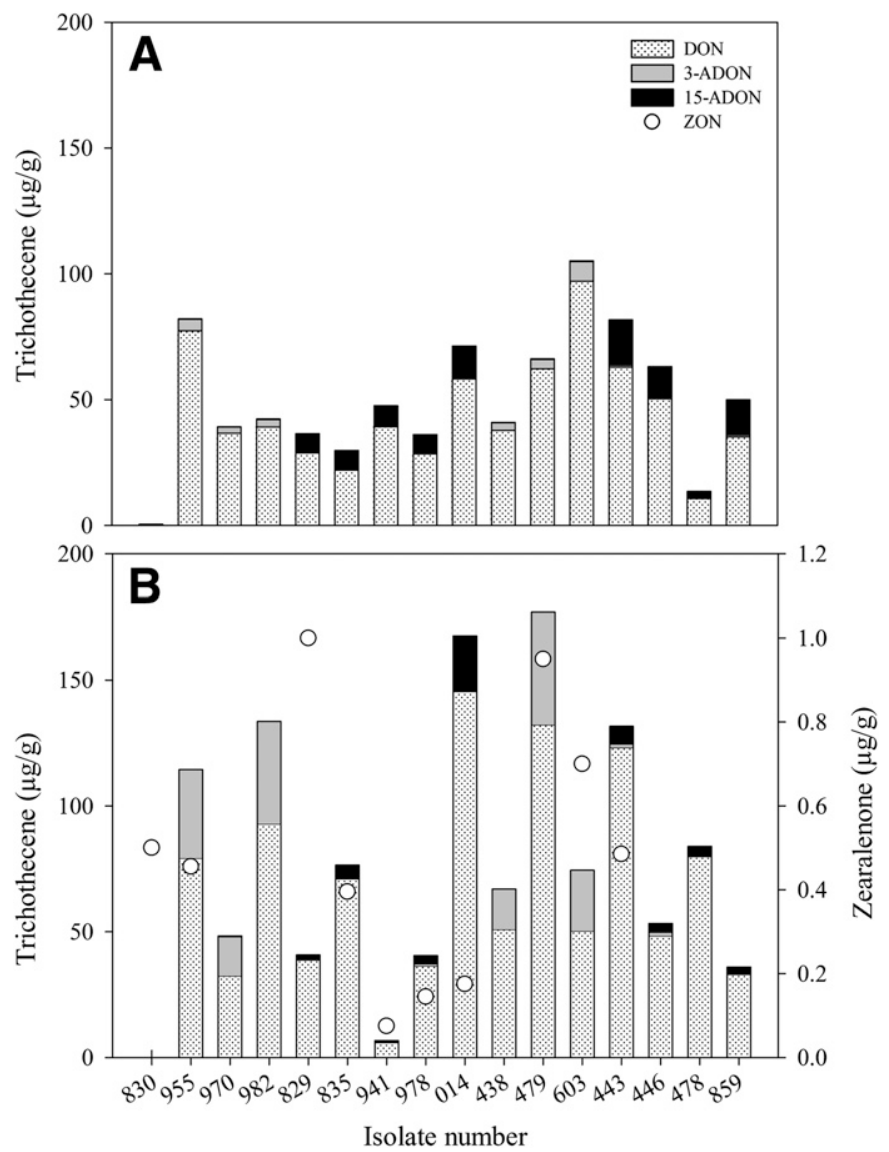

Fig. 2. Deoxynivalenol (DON), acetylated derivatives, and zearalenone (ZON) production in $\mathbf{A}$, wheat kernels and $\mathbf{B}$, maize kernels of 16 Fusarium graminearum isolates from wheat spikes and maize ears possessing either a 3-acetylDON (3-ADON) or a 15-ADON trichothecene genotype.
Despite differences between isolates grouped by chemotype or host of origin, a significant positive correlation was found between the total trichothecene accumulation and FHB severity in wheat $(r=$ $0.64 ; P=0.011)$ and GER severity in maize $(r=0.52, P=0.057)$ (data not shown).

MSB. The inoculations resulted in high seed infestation (100\%) and seed infection (>90\%) levels by all isolates with no apparent negative effect on the germination rate. Seedling blight scores did not differ $(P=0.098)$ between isolates from wheat $(48 \%)$ and those from maize (40\%) (Fig. 1C). No significant difference $(P=0.079)$ was found between $3-\mathrm{ADON}$ and $15-\mathrm{ADON}$ isolates for seedling blight incidence that ranged from 25 to $58 \%$ (Fig. 1C). Moreover, no significant difference $(P>0.05)$ was observed for all variables related to the reduction of plant growth. On average, reduction in length of shoot and radicle, and dry weight of shoot and radicle were $42,18,57$, and $62 \%$, respectively (Fig. 3).

\section{DISCUSSION}

We did not find evidence of host species/organ preference by any group of isolates based on the aggressiveness measures. Though not statistically significant, there was a trend for the isolates from wheat being slightly more aggressive and producing more DON than maize isolates, and in general, producing higher levels of severity of GER, FHB, and MSB. Aggressiveness is a very complex trait, yet specific genes and quantitative trait loci (QTL) in F. graminearum have been linked to aggressiveness (15). Specific host-isolate interactions could trigger a directed response by $F$. graminearum populations to adapt to increased host resistance $(17,58)$. Voss et al.'s (60) study on variation and transgressive segregation of aggressiveness among progeny from two $F$. graminearum crosses developed from highly aggressive parental isolates suggested that an incremental approach to increasing disease resistance also might result in an incremental increase in aggressiveness within the pathogen population. Several QTL have been linked to FHB resistance in wheat, remarkably $F h b 1$ (20 to $40 \%$ of phenotypic variation in the mapping populations) which is routinely used in wheat breeding in United States and Canada (39). On the other hand, GER resistance in maize is much less understood, and only two QTL are known to have some effect (37). The higher selection pressure imposed by wheat breeding than maize breeding with increased FHB resistance that depends on a few QTL could select for aggressiveness or increased mycotoxin production. This direct selection may not be rapid (60). In the long term, however, increasing aggressiveness and mycotoxin levels in populations of F. graminearum may occur in response to host resistance (16).

Our results suggested that isolates that were highly aggressive in one host/organ might not be highly aggressive in another host/ organ. However, even in a different host, it has been reported that $F$. graminearum possesses virulence factors that were common to FHB in wheat and seedling rot in soybean (56). Shared virulence on rotational crops might be involved in increase occurrence of soybean seedling diseases caused by $F$. graminearum in recent years in some parts of North and South America $(3,6)$. Also, a study with more than a hundred isolates of $F$. graminearum recovered from maize and soybean seedlings from 13 Ohio counties found that all isolates were highly pathogenic toward maize seed but moderately pathogenic on soybean seed (9). Hence further research is needed to better understand the influence of a rotation system with these three crops on the ecology and epidemiology of $F$. graminearum populations.

In this study, strains of $F$. graminearum from New York showed wide variation in aggressiveness toward wheat and maize that could not be structured by chemotype, and that corroborates previous findings of aggressiveness on wheat heads $(26,27,49,57)$, maize ears $(38,43)$, and seedlings $(30,56)$. Our results are consistent with results of a study with a larger collection (50 isolates) of $F$. graminearum isolates from wheat in New York, in which 
3-ADON isolates did not possess any detectable fitness advantage over isolates with $15-\mathrm{ADON}$ isolates (57). Likewise, $F$. graminearum isolates inoculated into maize ears of two susceptible inbred lines showed variation in GER severity that could not be discriminated by chemotype (38). Conversely, studies with $F$. graminearum isolates from other parts of the United States and also from Canada showed that 3-ADON isolates were more aggressive on wheat than $15-\mathrm{ADON}$ isolates $(24,50)$. Sexual
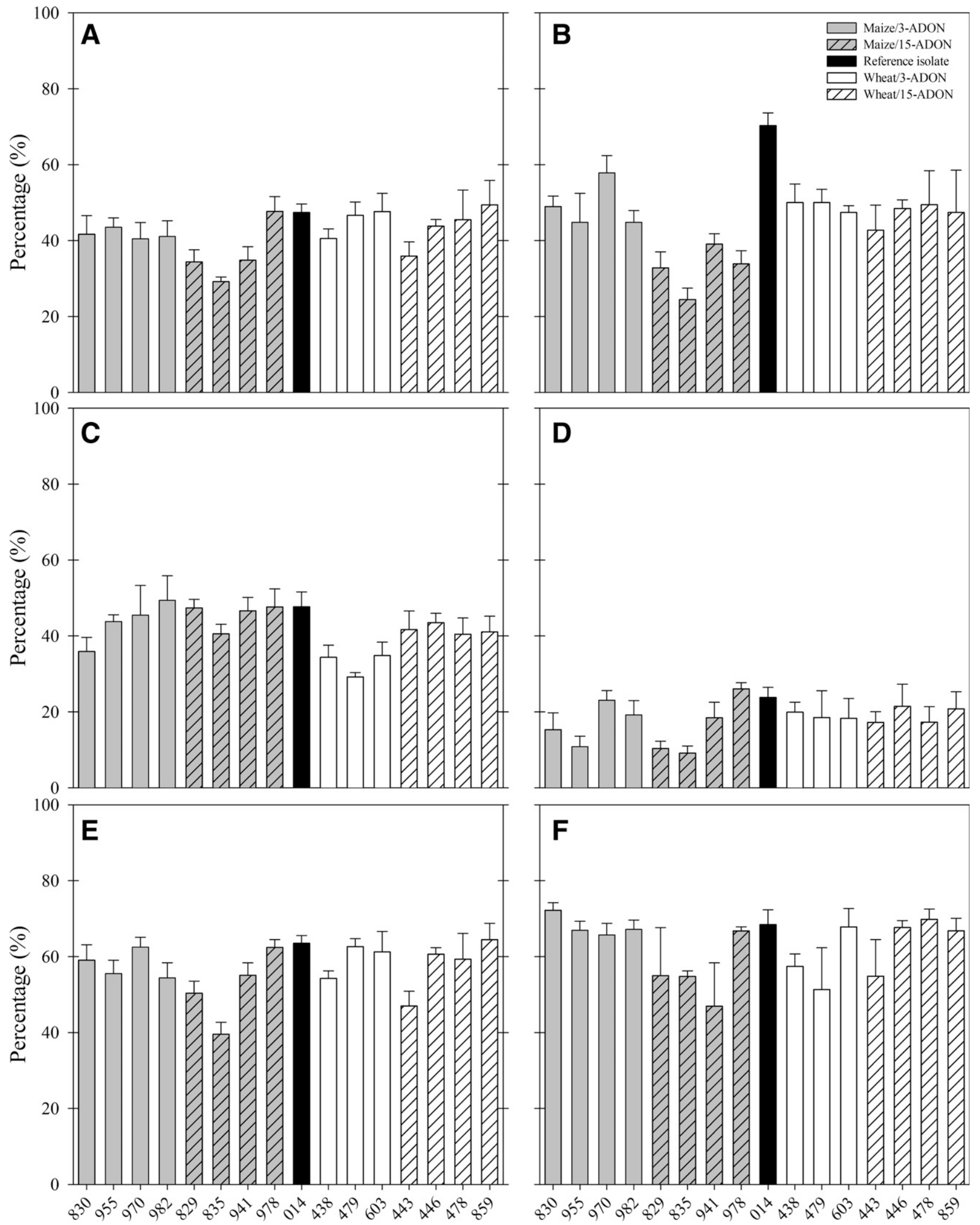

Isolates

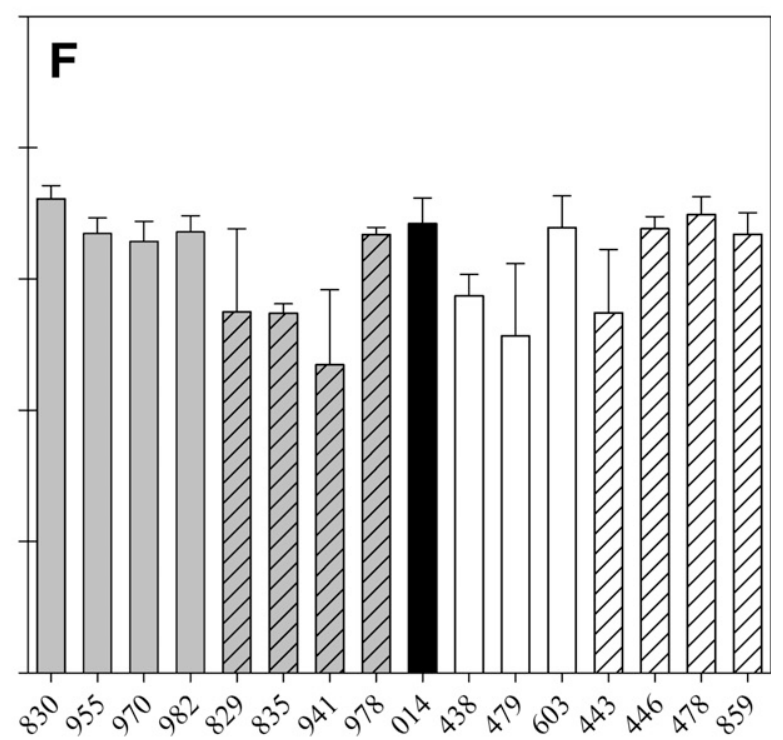

Isolates

Fig. 3. Pathogenic traits of 16 Fusarium graminearum isolates possessing either a 3-acetyl-deoxynivalenol (3-ADON) or a 15-ADON trichothecene genotype. A, Mean percent reduction of emergence, B, mean maize seedling blight severity, $\mathbf{C}$, mean percent reduction of shoot length, D, root length, E, shoot weight, and F, root weight at 14 days after planting. 
recombination between and within trichothecene genotype groups has been documented $(8,12)$; thus, genetic exchange between populations may occur and advantageous genes from each group may now be present in isolates of both trichothecene genotypes. Nevertheless, Ward et al. (63) suggested that 3-ADON isolates in North America resulted from a transcontinental introduction from Europe, and these two populations (3-ADON and 15-ADON) have been sympatric for too short a period to allow genetic exchange to break down population structure.

We also found large variation in DON production by the isolates irrespective of their chemotypes. Previous reports comparing DON production by chemotypes have been contradictory, and 3-ADON isolates may $(50,63)$ or may not $(26,57)$ produce higher levels of DON than 15-ADON isolates. The ability of $F$. graminearum isolates to produce large amounts of DON has been associated with aggressiveness (36). In a study with a collection of isolates of different members of the $F$. graminearum species complex, it was suggested that it was the total amount of trichothecenes rather than the specific type of trichothecene (DON or NIV) produced that affected aggressiveness on wheat (27). In our study, total trichothecenes, when adding together DON and acetylated derivatives, were significantly associated with FHB and GER, concurring with previous studies in wheat and maize $(27,29,32)$. Nevertheless Lemmens et al. (32) found that the relationship between visual symptoms and the amount of DON decreased at higher infection levels in wheat grains. Also, large variability in the relationship between DON and disease intensity measures was found in a study using meta-analysis of 126 fields in United States and Canada. Such variability might be due to other factors that influence this relationship, i.e., differential rates of DON production by $F$. graminearum isolates, cultivar resistance to FHB and DON accumulation, and weather conditions favorable for infection and growth of Fusarium head blight-causing fungi (44).

All but one isolate produced DON as the primary mycotoxin and lower amounts of the acetylated derivatives in wheat and maize kernels. Studies have suggested that the low amount of acetylated derivatives of DON found in inoculated or naturally infected kernels may be due to removal of the acetylated derivatives by converting $3-\mathrm{ADON}$ or $15-\mathrm{ADON}$ to DON (11). Moreover, the DON levels found, even for the least aggressive isolate, exceeded more than 10fold the maximum acceptable DON levels for human consumption, as is commonly observed in inoculated plants maintained under optimal conditions for the disease to develop (57).

Even though DON production has been reported as a virulence factor in wheat and maize $(5,28)$, we found one isolate (GZ830) of 3 -ADON genotype that did not produce DON or its acetylated derivatives in either wheat or maize kernels, yet was very aggressive toward both hosts. Mycotoxin production results from complex interactions between the host, the pathogen, and the environment $(13,32,36,67)$. Our discovery of a naturally occurring isolate that does not produce DON during infection of wheat or maize should be useful for further research to better understand the genetic bases of trichothecene regulation and the relation with aggressiveness (20).

We found that around $65 \%$ of the isolates produced small amounts of $\mathrm{ZON}$, an estrogenic compound responsible for reproductive disorders in humans and animals, and that may also contribute to plant pathogenesis $(53,66)$. This toxin was detected only in maize but not in wheat kernels. Although we did not investigate this question, it is possible that the absence of $\mathrm{ZON}$ in infected wheat kernels may be due to a detoxification mechanism in wheat (19).

As expected, 3-ADON and 15-ADON isolates produced higher amounts of the acetylated derivatives corresponding to their own genotype than the other, in kernels of both crops. Trace amounts of the other acetyl form were also detected in most of the isolates. It is more common to detect a mixture of DON and its acetylated derivatives in high proportion in in vitro culturing in grain-based or agar-based substrates where the fungus grows saprophytically (1).
In fact, the lack of correlation between in vitro and in planta (inoculated wheat heads) DON production has been demonstrated earlier (61). Similarly, pathogenic $F$. graminearum isolates were able to induce FHB symptoms in wheat heads and rice panicles while DON or NIV were produced only in wheat seeds and not in rice seeds (27), consistent with the observation that mycotoxins produced by the fungus in rice cultures often do not mimic those produced in host plant tissue $(10,33)$.

In summary, F. graminearum isolates from New York showed wide variation in aggressiveness and mycotoxin production toward susceptible wheat and maize. Neither host of origin nor trichothecene chemotype appeared to structure the populations we sampled. Though not significant, isolates from wheat were, on average, slightly more aggressive and toxigenic on ears of both hosts, thus suggesting that the relative pathogenic fitness of isolates from wheat versus maize should be tested with a substantially larger sample of isolates from both hosts. Our findings on pathogen variability support the strategy of prescreening pathogen isolates on target hosts and then utilizing isolates that are highly aggressive and toxigenic on the target host species when screening crop genotypes for resistance.

\section{ACKNOWLEDGMENTS}

We thank the Programa de Pós-graduação em Fitotecnia (UFRGS) and CNPq- Conselho Nacional de desenvolvimento Científico e Tecnológico for providing a graduate scholarship and a sandwich fellowship to P. R. Kuhnem and to CNPq for providing a research fellowship to E. M. Del Ponte. Laboratory, greenhouse, and field expenditures for this project were provided by Cornell University Hatch Project NYC153473.

\section{LITERATURE CITED}

1. Alexander, N. J., McCormick, S. P., Waalwijk, C., van der Lee, T., and Proctor, R. H. 2011. The genetic basis for 3-ADON and 15-ADON trichothecene chemotypes in Fusarium. Fungal Genet. Biol. 48: 485-495

2. Arias, M. M. D., Leandro, L. F., and Munkvold, G. P. 2013. Aggressiveness of Fusarium species and impact of root infection on growth and yield of soybeans. Phytopathology 103:822-832.

3. Arias, M. M. D., Munkvold, G. P., Ellis, M. L., and Leandro, L. F. S. 2013. Distribution and frequency of Fusarium species associated with soybean roots in Iowa. Plant Dis. 97:1557-1562.

4. Backhouse, D. 2014. Global distribution of Fusarium graminearum, $F$. asiaticum and F. boothii from wheat in relation to climate. Eur. J. Plant Pathol. 139:161-173.

5. Bai, G. H., Desjardins, A. E., and Plattner, R. D. 2002. Deoxynivalenolnonproducing Fusarium graminearum causes initial infection, but does not cause disease spread in wheat spikes. Mycopathologia 153:91-98.

6. Barros, G. G., Zanon, M. S. A., Chiotta, M. L., Reynoso, M. M., Scandiani, M. M., and Chulze, S. N. 2013. Pathogenicity of phylogenetic species in the Fusarium graminearum complex on soybean seedlings in Argentina. Eur. J. Plant Pathol. 138:215-222.

7. Boutigny, A.-L., Ward, T. J., Van Coller, G. J., Flett, B., Lamprecht, S. C., O'Donnell, K., and Viljoen, A. 2011. Analysis of the Fusarium graminearum species complex from wheat, barley and maize in South Africa provides evidence of species-specific differences in host preference. Fungal Genet. Biol. 48:914-920.

8. Bowden, R. L., and Leslie, J. F. 1999. Sexual recombination in Gibberella zeae. Phytopathology 89:182-188.

9. Broders, K. D., Lipps, P. E., Paul, P. A., and Dorrance, A. E. 2007. Evaluation of Fusarium graminearum associated with corn and soybean seed and seedling disease in Ohio. Plant Dis. 91:1155-1160.

10. Burlakoti, R., Ali, S., Secor, G. A., Neate, S. M., McMullen, M. P., and Adhikari, T. B. 2008. Comparative mycotoxin profiles of Gibberella zeae populations from barley, wheat, potatoes, and sugar beets. Appl. Environ. Microbiol. 74:6513-6520.

11. Burlakoti, R. R., Ali, S., Secor, G. A., Neate, S. M., McMullen, M. P., and Adhikari, T. B. 2008. Genetic relationships among populations of Gibberella zeae from barley, wheat, potato, and sugar beet in the upper Midwest of the United States. Phytopathology 98:969-976.

12. Chen, Y., and Zhou, M.-G. 2009. Characterization of Fusarium graminearum isolates resistant to both carbendazim and a new fungicide JS39919. Phytopathology 99:441-446. 
13. Cowger, C., Patton-Ozkurt, J., Brown-Guedira, G., and Perugini, L. 2009. Post-anthesis moisture increased Fusarium head blight and deoxynivalenol levels in North Carolina winter wheat. Phytopathology 99: 320-327.

14. Creppy, E. E. 2002. Update of survey, regulation and toxic effects of mycotoxins in Europe. Toxicol. Lett. 127:19-28.

15. Cumagun, C. J. R., Bowden, R. L., Jurgenson, J. E., Leslie, J. F., and Miedaner, T. 2004. Genetic mapping of pathogenicity and aggressiveness of Gibberella zeae (Fusarium graminearum) toward wheat. Phytopathology 94:520-526.

16. Cumagun, C. J. R., and Miedaner, T. 2004. Segregation for aggressiveness and deoxynivalenol production of a population of Gibberella zeae causing head blight of wheat. Eur. J. Plant Pathol. 110:789-799.

17. Cumagun, C. J. R., Rabenstein, F., and Miedaner, T. 2004. Genetic variation and covariation for aggressiveness, deoxynivalenol production and fungal colonization among progeny of Gibberella zeae in wheat. Plant Pathol. 53:446-453.

18. Del Ponte, E. M., Fernandes, J. M. C., and Bergstrom, G. C. 2007. Influence of growth stage on Fusarium head blight and deoxynivalenol production in wheat. J. Phytopathol. 155:577-581.

19. Desjardins, A. 2006. Fusarium Mycotoxins: Chemistry, Genetics, and Biology. American Phytopathological Society, St. Paul, MN.

20. Desjardins, A. E., Hohn, T. M., and McCormick, S. P. 1993. Trichothecene biosynthesis in Fusarium species: Chemistry, genetics, and significance. Microbiol. Mol. Biol. Rev. 57:595-604.

21. Desjardins, A. E., and Proctor, R. H. 2011. Genetic diversity and trichothecene chemotypes of the Fusarium graminearum clade isolated from maize in Nepal and identification of a putative new lineage. Fungal Biol. 115:38-48

22. Dill-Macky, R., and Jones, R. K. 2000. The effect of previous crop residues and tillage on Fusarium head blight of wheat. Plant Dis. 84: 71-76.

23. Engle, J., Madden, L., and Lipps, P. 2003. Evaluation of inoculation methods to determine resistance reactions of wheat to Fusarium graminearum. Plant Dis. 87:1530-1535.

24. Foroud, N. A., McCormick, S. P., MacMillan, T., Badea, A., Kendra, D. F., Ellis, B. E., and Eudes, F. 2012. Greenhouse studies reveal increased aggressiveness of emergent Canadian Fusarium graminearum chemotypes in wheat. Plant Dis. 96:1271-1279.

25. Gilbert, J., Brûlé-Babel, A., Guerrieri, A. T., Clear, R. M., Patrick, S., Slusarenko, K., and Wolfe, C. 2014. Ratio of 3-ADON and 15-ADON isolates of Fusarium graminearum recovered from wheat kernels in Manitoba from 2008 to 2012. Can. J. Plant Pathol. 36:54-63.

26. Gilbert, J., Clear, R. M., Ward, T. J., Gaba, D., Tekauz, A., Turkington, T. K., Woods, S. M., Nowicki, T., and O'Donnell, K. 2010. Relative aggressiveness and production of 3- or 15-acetyl deoxynivalenol and deoxynivalenol by Fusarium graminearum in spring wheat. Can. J. Plant Pathol. 32:146-152.

27. Goswami, R. S., and Kistler, H. C. 2005. Pathogenicity and in planta mycotoxin accumulation among members of the Fusarium graminearum species complex on wheat and rice. Phytopathology 95:1397-1404.

28. Harris, L., and Desjardins, A. 1999. Possible role of trichothecene mycotoxins in virulence of Fusarium graminearum on maize. Plant Dis. 83:954-960.

29. Jin, F., Bai, G., Zhang, D., Dong, Y., Ma, L., Bockus, W., and Dowell, F. 2014. Fusarium-damaged kernels and deoxynivalenol in Fusariuminfected U.S. winter wheat. Phytopathology 104:472-478.

30. Kuhnem, P. R., Jr., Stumpf, R., Spolti, P., and Del Ponte, E. M. 2013. Características patogênicas de isolados do complexo Fusarium graminearum e de Fusarium verticillioides em sementes e plântulas de milho. Cienc. Rural 43:583-588.

31. Lee, S. H., Lee, J., Nam, Y. J., Lee, S., Ryu, J. G., and Lee, T. 2010. Population structure of Fusarium graminearum from maize and rice in 2009 in Korea. Plant Pathol. J. 26:321-327.

32. Lemmens, M., Buerstmayr, H., Krska, R., Schuhmacher, R., Grausgruber, H., and Ruckenbauer, P. 2004. The Effect of inoculation treatment and long-term application of moisture on Fusarium head blight symptoms and deoxynivalenol contamination in wheat grains. Eur. J. Plant Pathol. 110: 299-308.

33. Leslie, J. F., and Summerell, B. A. 2006. The Fusarium Laboratory Manual. Wiley Online Library, Ames, IA.

34. Maier, F. J., Miedaner, T., Hadeler, B., Felk, A., Salomon, S., Lemmens, M., Kassner, H., and Schaefer, W. 2006. Involvement of trichothecenes in fusarioses of wheat, barley and maize evaluated by gene disruption of the trichodiene synthase (Tri5) gene in three field isolates of different chemotype and virulence. Mol. Plant Pathol. 7:449-461.

35. McMullen, M., Bergstrom, G., De Wolf, E., Dill-Macky, R., Hershman, D., Shaner, G., and Van Sanford, D. 2012. A unified effort to fight an enemy of wheat and barley: Fusarium head blight. Plant Dis. 96:1712-1728.
36. Mesterházy, Á. 2002. Role of deoxynivalenol in aggressiveness of Fusarium graminearum and $F$. culmorum and in resistance to Fusarium head blight. Eur. J. Plant Pathol. 108:675-684.

37. Mesterházy, Á., Lemmens, M., and Reid, L. 2012. Breeding for resistance to ear rots caused by Fusarium spp. in maize-A review. Plant Breed. 131:1-19.

38. Miedaner, T., Bolduan, C., and Melchinger, A. E. 2010. Aggressiveness and mycotoxin production of eight isolates each of Fusarium graminearum and Fusarium verticillioides for ear rot on susceptible and resistant early maize inbred lines. Eur. J. Plant Pathol. 127:113-123.

39. Miedaner, T., and Korzun, V. 2012. Marker-assisted selection for disease resistance in wheat and barley breeding. Phytopathology 102:560-566.

40. Miller, J. D., Greenhalgh, R., Wang, Y., and Lu, M. 1991. Trichothecene chemotypes of three Fusarium species. Mycologia 83:121-130.

41. Mudge, A. M., Dill-Macky, R., Dong, Y., Gardiner, D. M., White, R. G., and Manners, J. M. 2006. A role for the mycotoxin deoxynivalenol in stem colonisation during crown rot disease of wheat caused by Fusarium graminearum and Fusarium pseudograminearum. Physiol. Mol. Plant Pathol. 69:73-85.

42. Munkvold, G. P. 2003. Epidemiology of Fusarium diseases and their mycotoxins in maize ears. Eur. J. Plant Pathol. 109:705-713.

43. Munkvold, G. P., and O’Mara, J. K. 2002. Laboratory and growth chamber evaluation of fungicidal seed treatments for maize seedling blight caused by Fusarium species. Plant Dis. 86:143-150.

44. Paul, P. A., Lipps, P. E., and Madden, L. V. 2006. Meta-analysis of regression coefficients for the relationship between Fusarium head blight and deoxynivalenol content of wheat. Phytopathology 96:951-961.

45. Pereyra, S. A., and Dill-Macky, R. 2008. Colonization of the residues of diverse plant species by Gibberella zeae and their contribution to Fusarium head blight inoculum. Plant Dis. 92:800-807.

46. Pereyra, S. A., Dill-Macky, R., and Sims, A. L. 2004. Survival and inoculum production of Gibberella zeae in wheat residue. Plant Dis. 88: 724-730.

47. Pestka, J. J. 2010. Deoxynivalenol: Mechanisms of action, human exposure, and toxicological relevance. Arch. Toxicol. 84:663-679.

48. Purahong, W., Alkadri, D., Nipoti, P., Pisi, A., Lemmens, M., and Prodi, A. 2011. Validation of a modified Petri-dish test to quantify aggressiveness of Fusarium graminearum in durum wheat. Eur. J. Plant Pathol. 132: 381-391

49. Purahong, W., Nipoti, P., Pisi, A., Lemmens, M., and Prodi, A. 2014. Aggressiveness of different Fusarium graminearum chemotypes within a population from Northern-Central Italy. Mycoscience 55:63-69.

50. Puri, K. D., and Zhong, S. 2010. The 3ADON population of Fusarium graminearum found in North Dakota is more aggressive and produces a higher level of DON than the prevalent 15ADON population in spring wheat. Phytopathology 100:1007-1014.

51. Reid, L., Hamilton, R., and Mather, D. 1995. Effect of macroconidial suspension volume and concentration on expression of resistance to Fusarium graminearum in maize. Plant Dis. 79:461-466.

52. Reid, L., Woldemariam, T., Zhu, X., Stewart, D. W., and Schaafsma, A. W. 2002. Effect of inoculation time and point of entry on disease severity in Fusarium graminearum, Fusarium verticillioides, or Fusarium subglutinans inoculated maize ears. Can. J. Plant Pathol. 24:162-167.

53. Repka, V., Fiala, R., Luxová, M., and Pavlovkin, J. 2013. Responses of maize root cells to zearalenone and its derivatives $\alpha$-zearalenol and $\beta$-zearalenol. Eur. J. Plant Pathol. 138:787-797.

54. Sampietro, D. A., Díaz, C. G., Gonzalez, V., Vattuone, M. A., Ploper, L. D., Catalan, C. A. N., and Ward, T. J. 2011. Species diversity and toxigenic potential of Fusarium graminearum complex isolates from maize fields in northwest Argentina. Int. J. Food Microbiol. 145:359-364.

55. Schmale, D. G., III, Leslie, J. F., Zeller, K. A., Saleh, A. A., Shields, E. J., and Bergstrom, G. C. 2006. Genetic structure of atmospheric populations of Gibberella zeae. Phytopathology 96:1021-1026.

56. Sella, L., Gazzetti, K. G., Castiglioni, C., Schäfer, W., and Favaron, F. 2014. Fusarium graminearum possesses virulence factors common to Fusarium head blight of wheat and seedling rot of soybean, but differing in their impact on disease severity. Phytopathology 104:1201-1207.

57. Spolti, P., Del Ponte, E. M., Cummings, J. A., Dong, Y., and Bergstrom, G. C. 2014. Fitness attributes of Fusarium graminearum isolates from wheat in New York possessing a 3-ADON or 15-ADON trichothecene genotype. Phytopathology 104:513-519.

58. Talas, F., Würschum, T., Reif, J. C., Parzies, H. K., and Miedaner, T. 2012. Association of single nucleotide polymorphic sites in candidate genes with aggressiveness and deoxynivalenol production in Fusarium graminearum causing wheat head blight. BMC Genet. 13:14.

59. Torres, P. S., Quaglino, M. B., and Pillar, V. D. 2010. Properties of a randomization test for multifactor comparisons of groups. J. Stat. Comput. Simul. 80:1131-1150.

60. Voss, H.-H., Bowden, R. L., Leslie, J. F., and Miedaner, T. 2010. Variation and transgression of aggressiveness among two Gibberella zeae crosses 
developed from highly aggressive parental isolates. Phytopathology 100: 904-912.

61. Walker, S. L., Leath, S., Hagler, W. M., and Murphy, J. P. 2001. Variation among isolates of Fusarium graminearum associated with Fusarium head blight in North Carolina. Plant Dis. 85:404-410.

62. Ward, T. J., Bielawski, J. P., Kistler, H. C., Sullivan, E., and O'Donnell, K. 2002. Ancestral polymorphism and adaptive evolution in the trichothecene mycotoxin gene cluster of phytopathogenic Fusarium. Proc. Natl. Acad. Sci. USA 99:9278.

63. Ward, T. J., Clear, R. M., Rooney, A. P., O'Donnell, K., Gaba, D., Patrick, S., Starkey, D. E., Gilbert, J., Geiser, D. M., and Nowicki, T. W. 2008. An adaptive evolutionary shift in Fusarium head blight pathogen populations is driving the rapid spread of more toxigenic Fusarium graminearum in North America. Fungal Genet. Biol. 45:473-484.
64. Wilke, A. L., Bronson, C. R., Tomas, A., and Munkvold, G. P. 2007. Seed transmission of Fusarium verticillioides in maize plants grown under three different temperature regimes. Plant Dis. 91:1109-1115.

65. Wu, A. B., Li, H. P., Zhao, C. S., and Liao, Y. C. 2005. Comparative pathogenicity of Fusarium graminearum isolates from China revealed by wheat coleoptile and floret inoculations. Mycopathologia 160:75-83.

66. Yazar, S., and Omurtag, G. Z. 2008. Fumonisins, trichothecenes and zearalenone in cereals. Int. J. Mol. Sci. 9:2062-2090.

67. Yoshida, M., and Nakajima, T. 2010. Deoxynivalenol and nivalenol accumulation in wheat infected with Fusarium graminearum during grain development. Phytopathology 100:763-773.

68. Zeller, K. A., Bowden, R. L., and Leslie, J. F. 2003. Diversity of epidemic populations of Gibberella zeae from small quadrats in Kansas and North Dakota. Phytopathology 93:874-880. 